\title{
Mobilidade socioeconômica no Brasil, padrão de consumo e conflitos socioambientais *
}

\author{
Fernando Sertã Meressi ${ }^{* *}$ \\ Maria de Fátima Souza e Silva ***
}

\section{Resumo}

A ampliação, verificada neste artigo, do número de brasileiros nas classes média e alta, proporcionada, em larga medida, por algumas importantes políticas públicas, produz reflexos na elevação do padrão de consumo. O incremento da renda também vem sendo observado em outros populosos países do Sul, o que acirra o conflito socioambiental entre ricos e pobres em escala mundial, dado o já ambientalmente insustentável padrão de vida vigente nos países do Norte e entre as elites econômicas do Sul. Quais populações deveriam arcar com os sacrifícios econômicos necessários à sustentabilidade do planeta? Quais questões são suscitadas por um processo de arrefecimento econômico que vise ao desenvolvimento sustentável, levando-se em conta um contexto de economia capitalista? Como as novas tecnologias se inserem nesse processo? Esses são os temas principais discutidos neste artigo.

Palavras-chave: Mobilidade socioeconômica; Padrão de consumo; Conflito socioambiental; Renda média; Renda alta.

\section{Abstract \\ Socioeconomic mobility in Brazil, consumption pattern and socio-environmental conflicts}

The increase in the number of Brazilians in the middle and upper classes, largely as a result of a number of important public policies, has caused a rise in the standard of consumption. The increase in income has also been observed in other populous countries in the South, which exacerbates the environmental conflict between the rich and the poor on a global scale, given the already environmentally unsustainable standard of living prevailing in the North and among the economic elites of the South. Which countries should bear the economic sacrifices of a sustainable planet? What issues are raised by a possible economic slowdown process aimed at sustainable development, taking into account the context of a capitalist economy? How do new technologies fit into this process? These are the main topics discussed in this article.

Keywords: Socioeconomic mobility; Consumption patterns; Environmental conflict; Medium income; High income.

JEL A12, O13, P10, P46, Q34.

* Artigo recebido em 14 de junho de 2013 e aprovado em 8 de janeiro de 2016.

** Doutorando no Programa de Pós-Graduação em Desenvolvimento, Sociedade e Cooperação Internacional, do Centro de Estudos Avançados Multidisciplinares, da Universidade de Brasília (UnB), Brasília, DF, Brasil. E-mail: sertameressi@gmail.com.

*** Professora no Programa de Pós-Graduação em Desenvolvimento, Sociedade e Cooperação Internacional, do Centro de Estudos Avançados Multidisciplinares, da Universidade de Brasília, Brasília, DF, Brasil. E-mail: souesil@unb.br. 


\section{Introdução}

Este artigo tem como objetivo analisar a relação entre a mobilidade socioeconômica da população brasileira vivenciada recentemente até $2011^{1}$, as prováveis mudanças no padrão de consumo por ela provocada e seus impactos na sustentabilidade ambiental. Além desta introdução, na seção 1, será observado como algumas políticas públicas implementadas nos últimos anos pelo governo brasileiro contribuíram para o maior dinamismo econômico, acompanhado de melhor distribuição de renda. Refere-se aqui à expansão creditícia, à ampliação das transferências de renda associadas à política social e à valorização real do salário mínimo.

$\mathrm{Na}$ seção 2, é apresentada a relação entre a ascendente mobilidade socioeconômica dos brasileiros e a tendência de elevação de seu padrão de consumo, tendo em vista que o contexto de crescimento econômico com melhorias na distribuição de renda teve como um de seus resultados a expansão do contingente populacional situado nas "classes" média e alta e a redução da população classificada no estrato mais baixo de renda ${ }^{2}$. Esta situação tende a elevar o padrão de consumo, visto que o acesso a alguns bens, como máquina de lavar roupa, microcomputador, carro e outros novos objetos lançados ultimamente - uma característica do que Baudrillard (1995) denominou Sociedade de Consumo -, ainda não está disseminado por todas as classes de renda.

Cabe informar que, para efeito da observação da mobilidade socioeconômica, considerou-se apenas o critério de renda, tendo como base os escritos da Comissão para Definição da Classe Média no Brasil, instituída pela Secretaria de Assuntos Estratégicos, da Presidência da República, contidos em Brasil $(2012, d)$. De posse dos limites inferiores e superiores de renda estipulados para a classe média pela referida Comissão, foi possível identificar o percentual da população encontrado nas classes de renda mais baixa, média e alta entre os anos de 2006 e 2011. Para tanto, foram utilizados dados sobre renda mensal domiciliar per capita, os quais estão disponíveis nos microdados das Pesquisas Nacionais por Amostra de Domicílios (PNADs), do Instituto Brasileiro de Geografia e Estatística (IBGE). Da mesma forma, os microdados da PNAD 2011 foram a base para a análise do padrão de consumo das diferentes classes de renda referente a esse ano.

A elevação do padrão de consumo de grande parcela da população brasileira - que dá os primeiros passos no caminho em direção ao patamar já atingido pelos cidadãos dos países desenvolvidos e pelas elites econômicas dos próprios países do

(1) Na ocasião de elaboração deste artigo, a Pesquisa Nacional por Amostra de Domicílios 2011 (PNAD), do Instituto Brasileiro de Geografia e Estatística (IBGE), era a edição mais recente. Tal pesquisa foi a base para a classificação da população brasileira dentro dos estratos de renda abordados neste artigo.

(2) Neste artigo, consideraremos classe de renda como sinônimo de estrato de renda. 
Sul - tende a contribuir para a melhoria de seu bem-estar, haja vista que parte expressiva de tal contingente ainda não conseguiu acessar as facilidades e comodidades proporcionadas pela modernidade, expressas em bens e serviços. Por outro lado, este crescente padrão de consumo deverá aumentar a pressão sobre os papéis do meio ambiente como provedor de energia e de matérias-primas e como receptáculo de resíduos, pressão essa já exercida em alta intensidade pelo atual padrão de consumo daquelas populações que já galgaram níveis de renda elevados. Este é o assunto tratado na seção 3, ressaltado que o fenômeno de elevação no patamar de renda também vem sendo experimentado por outros populosos países do Sul, como China e Índia, devendo expandir em um futuro não muito distante a "classe de novos consumidores globais", o que deverá acirrar os conflitos em torno da sustentabilidade ambiental em escala mundial.

Uma questão fundamental na pauta do desenvolvimento sustentável diz respeito a quem arcará com os sacrifícios socioeconômicos necessários à mitigação dos impactos ambientais, os quais se mostram insustentáveis segundo alguns indicadores, como as estimativas sobre o aquecimento global e a pegada ecológica ${ }^{3}$. Essa questão, portanto, grosso modo, tem três partes envolvidas: as populações pobres do Sul, as elites econômicas desses países e os habitantes dos países ditos desenvolvidos. Como será visto ao final deste artigo, a proposta - que se mostra semelhante àquela que decorre dos pensamentos de Daly (2013) -, é de que a população de alta renda, tanto do Norte quanto do Sul, arque em maior grau com tais sacrifícios, uma vez que esses segmentos já atingiram assaz elevado padrão de vida, de modo que incrementos em seu nível de renda levariam a uma situação de desperdício social. Feito isso, a redução desse desperdício poderia compensar, em certa medida, os impactos ambientais decorrentes da elevação do padrão de consumo da população de baixa renda.

Outra questão essencial em torno do desenvolvimento sustentável se refere ao modo de vida da sociedade contemporânea e à própria dinâmica do modo de produção capitalista, que persegue continuamente o crescimento econômico. Além dos capitalistas, outros atores, como trabalhadores e governos, geralmente, também almejam o crescimento, haja vista que o maior dinamismo econômico, muitas vezes, vem acompanhado de situação mais favorável no mercado de trabalho e de elevação

(3) Uma interessante definição de pegada ecológica pode ser obtida em Mello (2009). Segundo o referido autor, a pegada ecológica significa a quantidade de recursos naturais, especialmente terra e água, necessários para atender às necessidades e demandas de consumo de uma determinada população. É calculada a partir do somatório de todas as componentes do consumo relacionadas à geração de impactos ambientais. A pegada ecológica "representa as demandas críticas por capital natural de uma determinada economia ou população em termos das áreas biologicamente produtivas correspondentes e necessárias para satisfazer as demandas de tal economia ou população. Evidentemente, a área da pegada depende do tamanho da população, dos padrões e definições de qualidade de vida material, da tecnologia utilizada e da produtividade da economia ou sociedade em questão" (Mello, 2009, p. 125) 
da receita governamental. Daí o surgimento de grandes resistências quanto ao arrefecimento do crescimento em prol de maior controle do desequilíbrio ambiental, consistindo uma das principais ambiguidades apontadas pelo Desenvolvimento Sustentável.

Uma solução vislumbrada para compatibilizar os avanços socioeconômicos com a sustentabilidade ambiental consiste na ciência e tecnologia como instrumentos da ecoeficiência. Entretanto, o poder das novas tecnologias poupadoras de energia e matérias primas tem se mostrado insuficiente diante da manutenção do modus operandi do sistema de produção capitalista, de forma que os efeitos do crescimento econômico têm suplantado os benefícios, em termos de desmaterialização, proporcionados por essas novas tecnologias.

Em resumo, o estudo discute, a partir de dados e de proposições teóricas advindas de autores que tratam das dimensões econômica, social e ambiental do desenvolvimento, alguns conflitos que cercam o processo de desenvolvimento sustentável brasileiro.

\section{Crescimento econômico com distribuição de renda no Brasil}

Durante a década de 1990, a inflação foi a variável macroeconômica que mais atraiu a atenção dos economistas brasileiros. Com o Plano Real de estabilização, a inflação declinou a patamares aceitáveis. Todavia, nos primeiros anos que sucederam ao controle da escalada dos preços, o Brasil passou a conviver com elevada vulnerabilidade das contas externas, baixas taxas de crescimento da produção e desequilíbrio nas contas públicas. Este cenário, somado à incerteza decorrente da alternância de governo que resultaria na eleição do presidente Lula, fez com que o Real se desvalorizasse acentuadamente nos anos 2002 e 2003 e as taxas de juros fossem alçadas a patamares insustentáveis nesse período, de modo a evitar maior fuga de capitais.

Nos anos que se seguiram, essa tamanha desvalorização cambial, combinada com a fase de acelerado crescimento da economia global, terminou por ajustar a balança comercial e equilibrar as contas externas brasileiras, propiciando a redução dos juros, maiores taxas de crescimento do Produto Interno Bruto (PIB) e impactos positivos no emprego. Entretanto, além do PIB, se o objetivo do País era o desenvolvimento socioeconômico, uma grave enfermidade da sociedade brasileira tinha de ser combatida: a extrema concentração de renda, que produzia, entre seus resultados, elevados níveis de pobreza e miséria. Tendo isso em vista, três políticas públicas impulsionadas durante o governo Lula foram cruciais para alavancar o crescimento do PIB e distribuir renda: a expansão do crédito, a ampliação das 
transferências "progressivas"4 de renda associadas à política social e a política de valorização real do salário mínimo.

Quanto à expansão creditícia, o total das operações de crédito do Sistema Financeiro Nacional saltou de 25,7\% do PIB em fevereiro de 2003 para 49,1\% do PIB em dezembro de 2011, segundo Brasil (2012a), praticamente duplicando no período, com aumento crescente da participação dos bancos públicos neste processo. Do total dessa expansão, pode-se destacar as operações de crédito habitacional, as destinadas às pessoas físicas e as realizadas pelo Banco Nacional de Desenvolvimento Econômico e Social.

No que tange à ampliação das transferências progressivas de renda associadas à política social, os destaques ficaram a cargo da criação e expansão do Programa Bolsa Família e do aumento das despesas com benefícios previdenciários do Regime Geral de Previdência Social e assistenciais - dentre esses últimos, em especial, os Benefícios de Prestação Continuada, da Lei Orgânica de Assistência Social (BPC/LOAS) -, conforme apresentado nos Gráficos 1 e 2. No que se refere ao Programa Bolsa Família, o número de famílias beneficiárias foi mais do que duplicado entre 2004 e 2011, ao passo que, em termos de recursos despendidos, os valores nominais mais do que quadruplicaram. Quanto aos Benefícios Emitidos pelo INSS, o aumento entre 2003 e 2011 foi de $65 \%$ em termos reais.

\section{Gráfico 1}

Programa Bolsa Família - famílias atendidas (em milhões) e recursos despendidos (R \$ bilhões - preços correntes)

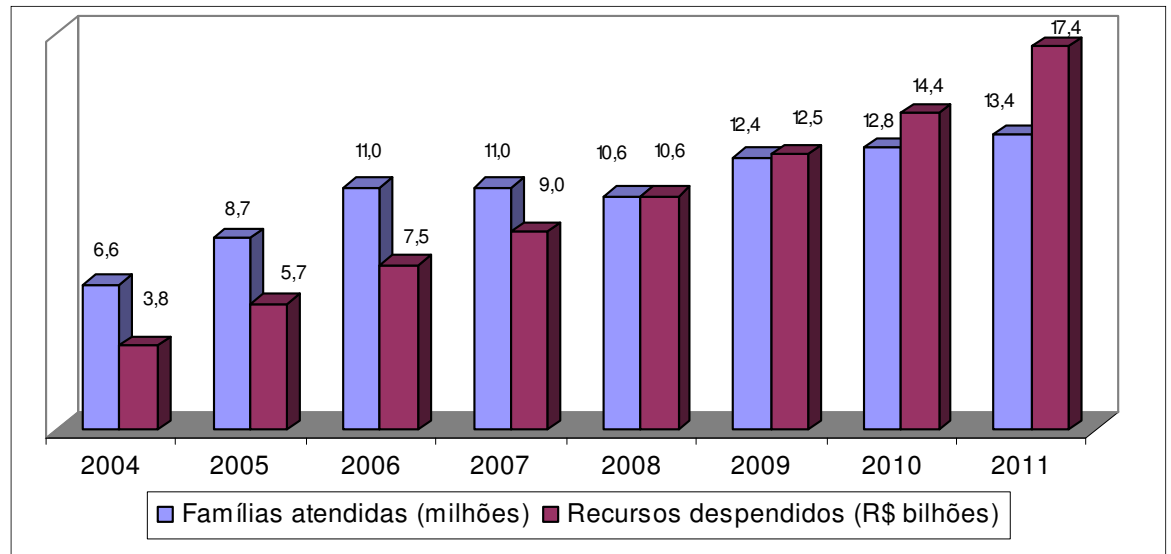

Fonte: Ministério do Desenvolvimento Social e Combate à Fome (MDS), Matriz de Informação Social. Disponível em: http://aplicacoes.mds.gov.br/sagi/mi2007/tabelas/mi_ social.php (Informação obtida em junho de 2013). Elaboração própria.

(4) O qualificativo de "progressivas" decorre do fato dessas transferências associadas à política social serem direcionadas majoritariamente aos mais pobres. Desse modo, contribuem para a distribuição de renda.

Economia e Sociedade, Campinas, v. 25, n. 1 (56), p. 87-108, abr. 2016.91 
Gráfico 2

Benefícios emitidos pelo INSS* - 2003 a 2011

(em R \$ bilhões - preços constantes**)

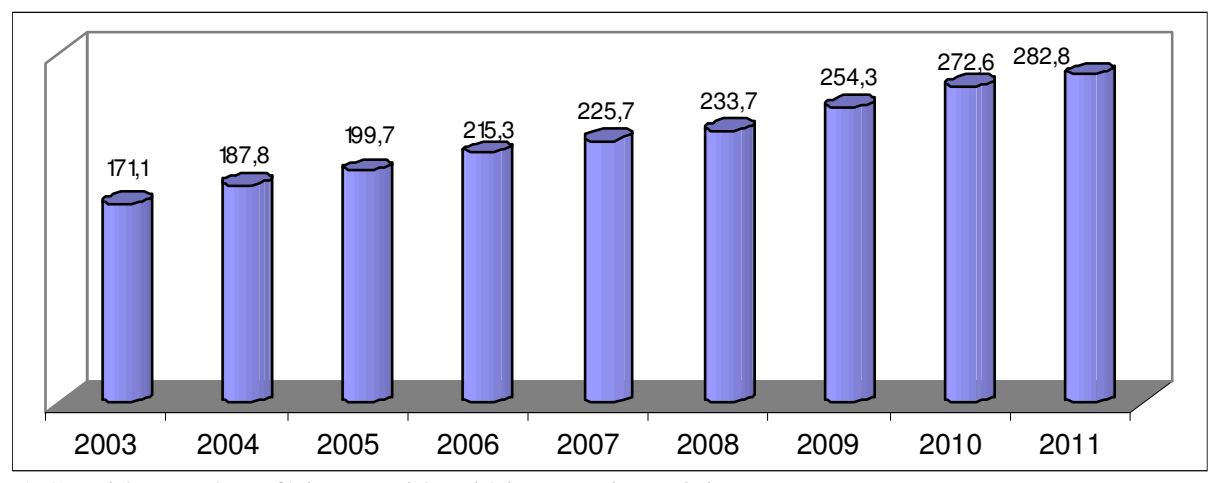

* Considera os benefícios previdenciários e assistenciais.

**Valores expressos em reais constantes, atualizados pelo Índice Nacional de Preços ao Consumidor - INPC mensal, a preços de abril de 2012.

Fonte: Boletim Estatístico da Previdência Social. Elaboração própria.

A política de valorização real do salário mínimo foi outro importante instrumento para dinamizar a economia e distribuir renda. Entre abril de 2002 e janeiro de 2012, o salário mínimo obteve aumento real de 65,9\%, segundo o Departamento Intersindical de Estatísticas e Estudos Socioeconômicos - DIEESE (2011). Cabe lembrar que grande parte do aumento das despesas com os benefícios previdenciários e assistenciais apresentado no Gráfico 2 se deve ao processo de valorização real do salário mínimo vigente nos últimos anos, haja vista que aproximadamente $67 \%$ desses benefícios são no valor de um salário mínimo (tais benefícios são indexados a esse referencial). Além de impactar a política social, os aumentos reais do salário mínimo também repercutem fortemente na economia como um todo, visto que, segundo o DIEESE (2011), em torno de 48 milhões de pessoas teriam seus rendimentos nele referenciados no início de 2012.

Desse modo, pode-se concluir que essas três políticas públicas cumpriram importante papel para dinamizar o mercado interno brasileiro, seja por ter ampliado o poder de compra por meio do crédito, seja pelo impulso ao consumo por meio do aumento da renda dos segmentos mais pobres, ou por ter contribuído para o incremento do salário médio da economia. Nesse mesmo sentido, o mercado de trabalho apresentou resultados positivos entre 2003 e 2011, os quais estão refletidos na queda da taxa de desocupação, na forte criação de empregos formais no setor privado e no aumento do salário real médio, conforme pode ser observado na Tabela 1. 
Tabela 1

Indicadores da situação do mercado de trabalho (2003-2011)

(Rendimento Médio Real a preços de maio / 2012)

\begin{tabular}{c|c|c|c}
\hline Ano & Taxa de Desocupação* & $\begin{array}{c}\text { Criação de empregos } \\
\text { formais celetistas } \\
(\mathrm{mil}) * *\end{array}$ & $\begin{array}{c}\text { Rendimento Médio Real } \\
\text { da População Ocupada } \\
(\mathrm{R} \$)^{*}\end{array}$ \\
\hline 2003 & 10,9 & 645,4 & $1.325,5$ \\
\hline 2004 & 9,6 & $1.523,3$ & $1.319,7$ \\
\hline 2005 & 8,4 & $1.254,0$ & $1.398,7$ \\
\hline 2006 & 8,4 & $1.228,7$ & $1.457,4$ \\
\hline 2007 & 7,5 & $1.617,4$ & $1.490,1$ \\
\hline 2008 & 6,8 & $1.452,2$ & $1.543,8$ \\
\hline 2009 & 6,8 & 995,1 & $1.555,2$ \\
\hline 2010 & 5,3 & $2.136,9$ & $1.647,3$ \\
\hline 2011 & 4,7 & $1.566,0$ & $1.689,8$ \\
\hline
\end{tabular}

* Posição dezembro. Refere-se às regiões metropolitanas de Recife, Salvador, Belo Horizonte, Rio de Janeiro, São Paulo e Porto Alegre.

** Saldo: admissões menos demissões.

Fonte: IBGE / Pesquisa Mensal de Emprego; CAGED / Ministério do Trabalho e Emprego.

Elaboração própria.

Assim, como decorrência direta das políticas sociais distributivas, da valorização real do salário mínimo e do aquecimento do mercado de trabalho, a renda dos mais pobres cresceu em um ritmo mais acelerado do que a dos mais ricos, melhorando a distribuição de renda. Como pode se constatar no Gráfico 3, o rendimento médio mensal real dos $20 \%$ mais pobres cresceu em torno de $75 \%$ entre 2004 e 2011, ao passo que o crescimento do rendimento dos $20 \%$ mais ricos não passou de $25 \%$ nesse mesmo período. Como resultado desse fenômeno, observar-seá, na próxima seção, a redução do percentual da população que se encontrava abaixo da linha de pobreza e que passou a se enquadrar nos estratos superiores de renda.

\section{Gráfico 3}

Crescimento (\%) do Rendimento Real dos Brasileiros entre 2004 e 2011

(Rendimento Médio Mensal Real, por decis de renda*) 


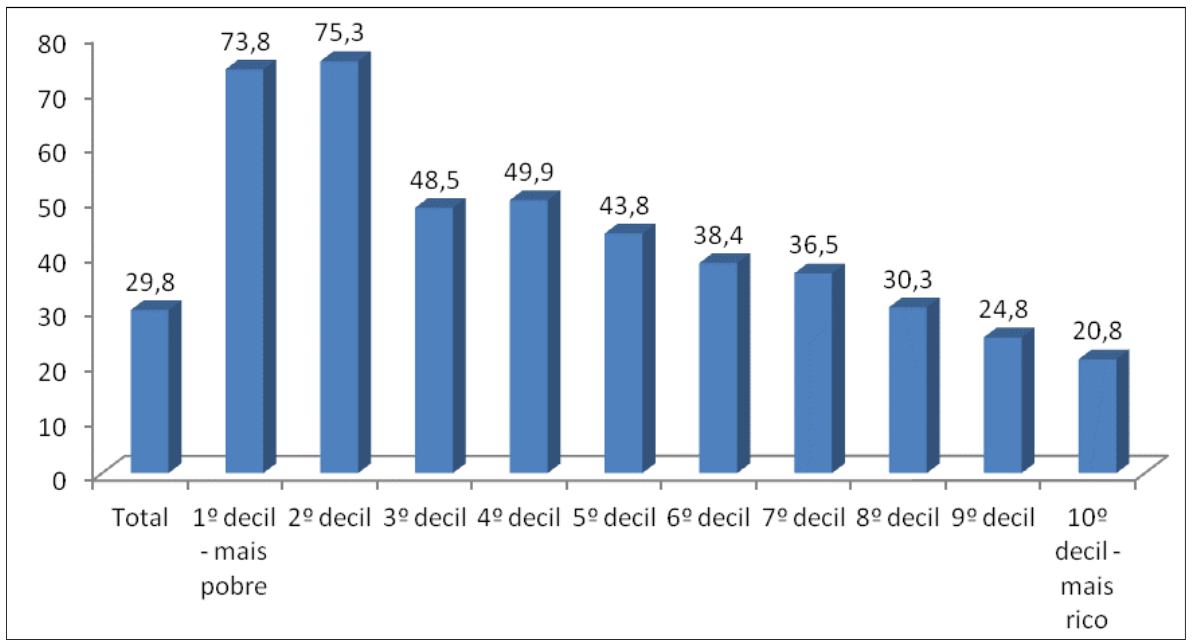

* Todos os trabalhos. Exclui as informações das pessoas sem declaração de rendimentos de todos os trabalhos. Valores inflacionados pelo INPC com base em setembro de 2011.

Fonte: Dados obtidos de Ministério da Fazenda / Brasil (2012b), que se baseou nas PNADs/IBGE.

\section{Mobilidade socioeconômica ascendente e tendência à elevação do padrão de consumo}

A partir da análise do processo de mobilidade socioeconômica experimentado no país entre 2006 e 2011, que será apresentada a seguir, constata-se o aumento do percentual da população situada nos estratos superiores de renda (classes média e alta), com redução do percentual enquadrado na classe econômica mais baixa. Sobre este fenômeno, desde já, há de se fazer algumas considerações. Primeiramente ${ }^{5}$, este trabalho está baseado nos limites de renda definidos para as classes de renda mais baixa, média e alta adotadas em Brasil (2012d) ${ }^{6}$. Esta mesma publicação faz ressalvas quanto ao limite inferior adotado para a classe média, no sentido de estar subestimado, haja vista que, nas Pesquisas Nacionais por Amostra de Domicílios (PNADs), que subsidiaram a definição desse limite, não há perguntas sobre rendas advindas de seguro-desemprego, abono salarial, décimo terceiro salário, horas extras eventuais, renda não monetária e outros ganhos. Feitas essas ressalvas, os limites considerados neste trabalho são os constantes da Tabela 2.

(5) Outras considerações serão apresentadas adiante, por ocasião da análise dos subestratos de renda.

(6) Limites entre as classes definidos pela Comissão para a Definição da Classe Média no Brasil, instituída pela Secretaria de Assuntos Estratégicos, da Presidência da República. 
Tabela 2

Limites para a definição da classe média

Renda bruta mensal normalmente recebida domiciliar per capita

Valores constantes de março de 2012

\section{Renda bruta mensal normalmente recebida domiciliar per capita}

(valores constantes de março de 2012)

$R \$ 1,00$

\begin{tabular}{c|c|c}
\hline Ano & Limite inferior da classe média & Limite superior da classe média \\
\hline 2006 & 214 & 749 \\
2007 & 221 & 775 \\
2008 & 234 & 819 \\
2009 & 248 & 867 \\
2010 & 261 & 914 \\
2011 & 277 & 971 \\
2012 & 291 & 1019 \\
\hline
\end{tabular}

Nota: segundo (2012d), o deflator utilizado foi o Índice Nacional de Preços ao Consumidor (INPC / IBGE).

Fonte: Brasil (2012d). Elaboração própria.

Tendo como base os limites acima e a partir das informações sobre renda obtidas das PNADs, podem ser calculados os percentuais da população brasileira situados nas classes de renda mais baixa, média e alta para os anos recentes ${ }^{7}$. Assim, tomando como referência a PNAD 2011, de 195,2 milhões de pessoas estimadas para o total da população brasileira, 184,1 milhões tiveram renda mensal domiciliar per capita informada na pesquisa, implicando a seguinte distribuição: 54,6 milhões de pessoas $(29,7 \%)$ enquadradas na classe de renda mais baixa; 92,7 milhões $(50,4 \%)$ na classe média; e 36,7 milhões na classe alta (20,0\%). A partir do Gráfico 4, observa-se o crescimento do percentual da população nas classes de renda mais elevadas e a redução do contingente situado na classe de renda mais baixa, constatando-se, entre 2006 e 2011, uma diminuição de 10,8 pontos percentuais (p.ps) na população pertencente à classe de renda mais baixa, o aumento de 6,5 p.ps no número de pessoas enquadradas na classe média e a elevação de 4,4 p.ps no contingente pertencente à classe alta.

Gráfico 4

(7) Não há informações da PNAD para 2010. Neste ano, em vez da PNAD, foi realizado o Censo Demográfico 2010, do IBGE.

Economia e Sociedade, Campinas, v. 25, n. 1 (56), p. 87-108, abr. 2016.95 
Percentual da população brasileira por estrato de renda (2006-2011) (limites entre as classes disposto na Tabela 2)

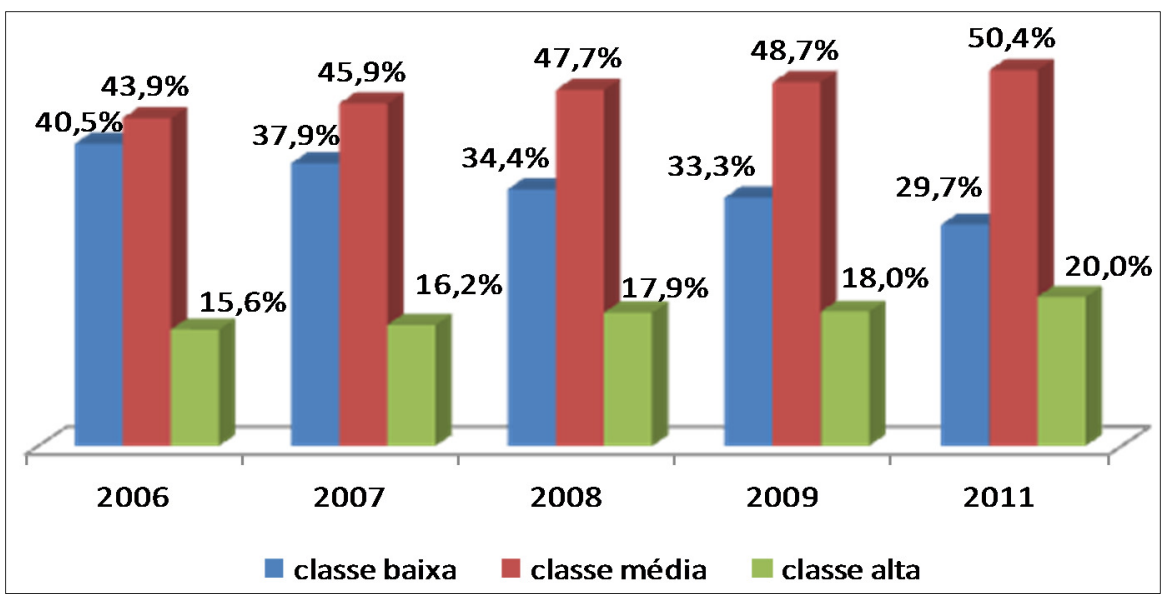

Nota: a classificação em cada estrato teve como base os limites definidos para a classe média na Tabela 2 e a variável da PNAD "rendimento mensal domiciliar per capita". Desconsideramos no cálculo as pessoas que não declararam suas rendas na mencionada pesquisa.

Fonte: Microdados das PNADs / IBGE. Elaboração própria.

Brasil (2012d) informa um quadro mais preciso da classificação dos brasileiros entre os estratos de renda ao subdividr cada um deles. Assim, segmenta a classe de renda mais baixa em três subestratos: extremamente pobres, pobres e vulneráveis, sendo este último referente à população que se situa acima da linha de pobreza, mas que ainda não se inseriu na classe média. Da mesma forma, divide a classe média em três categorias: baixa classe média, média classe média e alta classe média. Por fim, separa a classe alta em dois subestratos: baixa classe alta e alta classe alta. A Tabela 3 apresenta os limites de renda entre essas categorias para 2011. Desse modo, pode-se verificar, a partir do Gráfico 5, os percentuais da população brasileira em cada segmento de renda, cabendo uma consideração: os limites dos extremamente pobres e pobres, apesar de notadamente muito baixos, são próximos aos praticados por organismos internacionais - como o Banco Mundial -, estipulados, respectivamente, em US\$1,25 per capita por dia e US\$2,00 per capita por dia. 
Tabela 3

Limites entre os subestratos de renda - 2011

(Renda bruta mensal normalmente recebida domiciliar per capita)

$\mathrm{R} \$ 1,00$

\begin{tabular}{l|r}
\hline Subestratos & faixas de renda \\
\hline extremamente pobres & até 76 \\
\hline pobres & de 77 a 153 \\
\hline ulneráveis & de 154 a 276 \\
\hline baixa classe média & de 277 a 419 \\
\hline média classe média & de 420 a 609 \\
\hline alta classe média & de 610 a 971 \\
\hline baixa classe alta & de 972 a 2360 \\
\hline alta classe alta & acima de 2361 \\
\hline
\end{tabular}

Fonte: dados obtidos de Brasil (2012d), para o ano de 2012, cujos valores foram deflacionados para 2011 pelo mesmo índice de correção utilizado na Tabela 2. Segundo Brasil (2012d), utilizou-se como deflator o INPC/IBGE. Elaboração própria.

Gráfico 5

Percentual da população brasileira em cada subestrato de renda - 2011

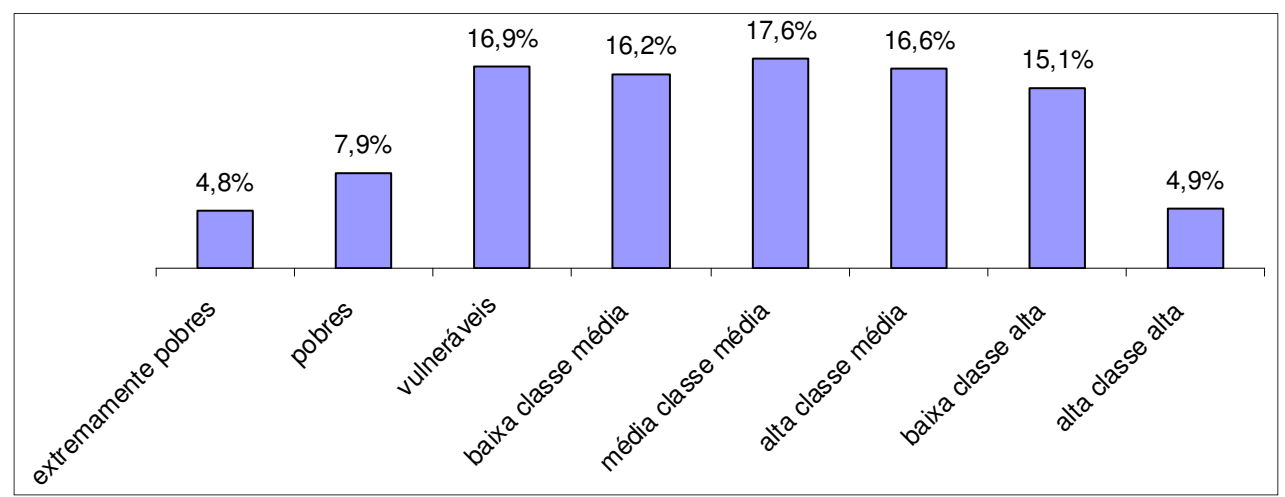

Nota: a classificação em cada subestrato teve como base os limites definidos na Tabela 3 e a variável da PNAD 2011 "rendimento mensal domiciliar per capita". Desconsideramos no cálculo as pessoas que não declararam suas rendas na mencionada pesquisa.

Fonte: Microdados da PNAD 2011/ IBGE. Elaboração própria.

Ainda que os dados apresentados sejam passíveis de diferentes interpretações e questionamentos, uma consequência do aumento da renda apontado aqui é a tendência de elevação do padrão de consumo. Tal elevação, se por um lado dinamiza a economia, impulsionando tanto o modelo de desenvolvimento fundamentado no paradigma da modernização quanto o próprio capitalismo, por 
outro, informa que o país ensaia os primeiros passos no caminho trilhado pelos países desenvolvidos e pelas elites econômicas dos países do Sul, no sentido da insustentabilidade ambiental de seus padrões de consumo. No entanto, há de se ressaltar que o Brasil pode ser classificado como um país de renda média, sendo a sua renda per capita muito inferior à dos países ditos desenvolvidos. A título de comparação, segundo o Banco Mundial ${ }^{8}$, a renda nacional bruta per capita brasileira foi de US $\$ 10.720$ em 2011, ou seja, correspondente a cerca de 1/4 da renda de alguns países ditos desenvolvidos, como os Estados Unidos (US\$ 48.620), a Alemanha (US\$ 44.230) e a França (US\$ 42.420). Em outras palavras, resta um longo caminho para que o Brasil atinja o patamar de consumo dos países do Norte, o que pode ser corroborado pelas passagens abaixo transcritas de Bursztyn e Bursztyn (2012, p. 296) ${ }^{9}$, que dão a dimensão do diferencial de consumo entre essas sociedades:

Em média, um habitante de um país industrializado consome nove vezes mais energia fóssil, seis vezes mais carne bovina, vinte vezes mais alumínio, dezesseis vezes mais cobre, e duas vezes e meia mais madeira, que um habitante de um país em desenvolvimento (Bontems; Rotillon, 1998).

Os 30 países membros da OCDE abrigam $18 \%$ da população mundial, mas consomem mais da metade da energia, mais de $60 \%$ dos cereais, $31 \%$ do peixe e $44 \%$ dos produtos florestais do planeta (OCDE, 2001).

Uma vez apresentado o enorme diferencial de consumo entre os habitantes dos países ditos desenvolvidos e os demais, os Gráficos 6 e 7 apresentam uma simplificação dos padrões de consumo dos brasileiros classificados nos três estratos de renda abordados neste trabalho, indicando que níveis superiores de aquisição virão pela frente, em persistindo a tendência de elevação da renda verificada nos últimos anos, o que tende a elevar o bem-estar das pessoas que experimentam a ascendente mobilidade socioeconômica. Com vistas a representar o padrão de cada estrato, foi selecionada uma cesta $a d$ hoc de bens, que permite a comparação entre esses estratos. Dessa forma, o Gráfico 6 apresenta a propriedade de bens bastante disseminados entre os domicílios brasileiros, de modo que não há tanta diferença entre os comportamentos das populações de cada segmento de renda. Por outro lado, o Gráfico 7 mostra bens que são adquiridos mais facilmente apenas pelos estratos de renda mais elevados, indicando que o aumento da renda impactará fortemente no consumo desses bens.

Gráfico 6

(8) Informação obtida de http://data.worldbank.org/, em maio de 2013.

(9) Embora os dados sejam relativamente antigos, fornecem uma ideia da abissal disparidade entre os padrões de consumo dessas sociedades. 
Percentual de domicílios que possuem bens mais disseminados - 2011

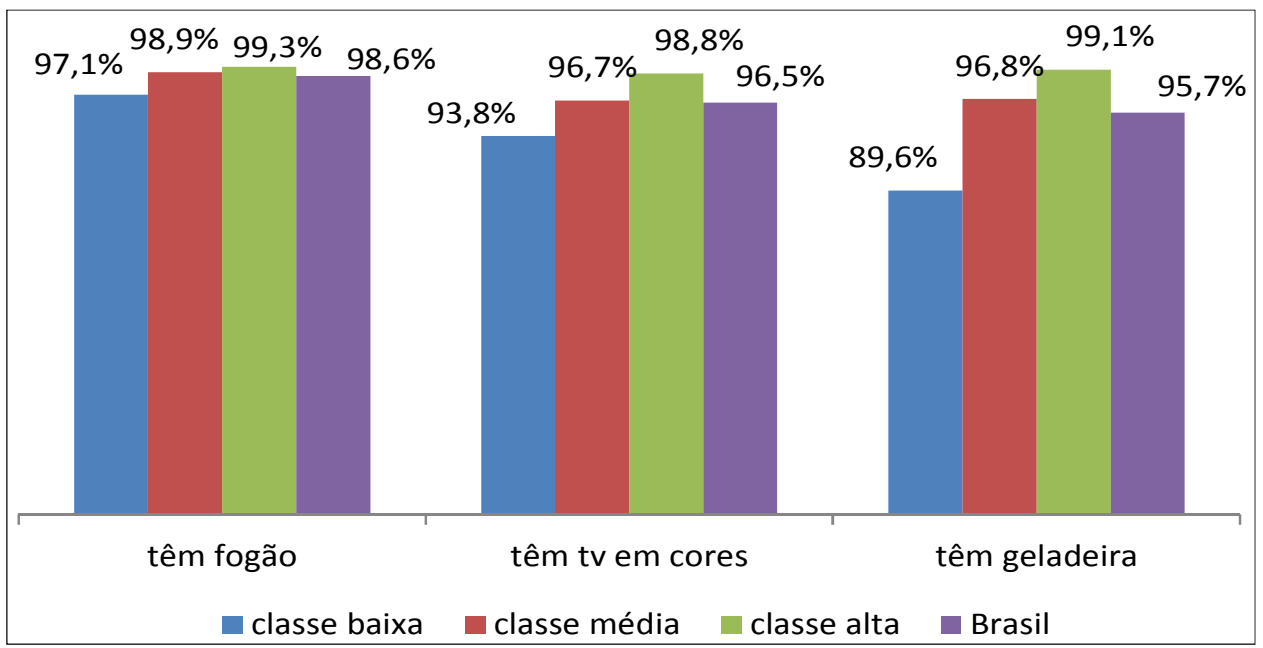

Nota: consideramos apenas fogões com duas bocas ou mais.

Fonte: Microdados da PNAD 2011. Elaboração própria.

Gráfico 7

Percentual de domicílios que possuem bens menos disseminados - 2011

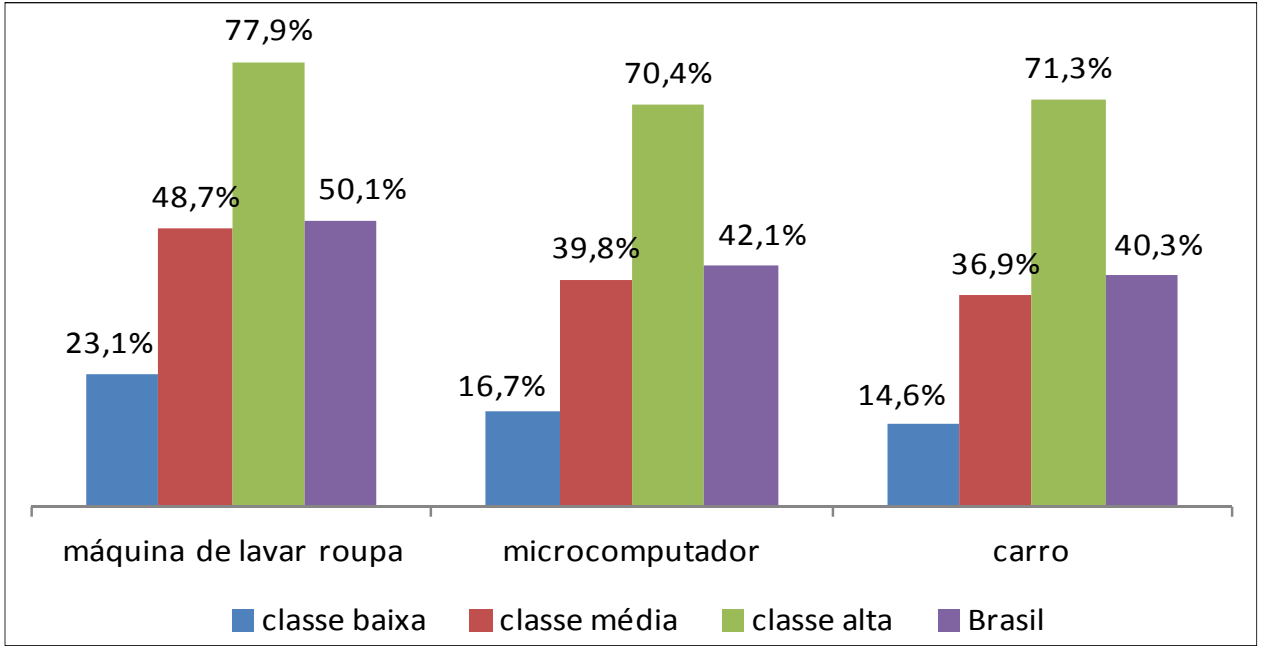

Fonte: Microdados da PNAD 2011. Elaboração própria.

Assim, ao permanecer a trajetória de incremento do número de pessoas tanto na classe média quanto na alta, e tendo em vista o diferencial entre as classes no que se refere à propriedade de alguns bens que ainda não foram "popularizados", inferese que o patamar de consumo da população brasileira será impulsionado. Assim, em que pesem os impactos ambientais negativos, cabe lembrar que o contingente da população brasileira que ainda não atingiu a classe média é elevado, uma vez que $29,7 \%$ ainda pertencia à classe mais baixa em 2011. Isto revela que essas pessoas, 
por serem extremamente pobres, pobres ou vulneráveis, ainda têm bastante dificuldade para satisfazer mesmo as necessidades mais básicas de sua sobrevivência, sendo o crescimento econômico uma das vias de acesso à superação de suas privações de bem-estar.

\section{Elevação do padrão de consumo e conflitos socioambientais}

Alguns indicadores, como o aquecimento global e a pegada ecológica, informam que o planeta está sendo explorado em um ritmo superior à sua capacidade de regeneração, seja no que diz respeito à provisão de recursos, seja na condição de receptáculo de resíduos. Tendo isso em vista, autores como Sawyer (2001 e 2002) e Ribemboim (1997) consideram o padrão de consumo vigente no mundo como a principal razão do desenvolvimento insustentável. De acordo com Sawyer (2001), dentre os três fatores que compõem a equação do impacto ambiental (população, afluência e tecnologia), a afluência, refletida no padrão de consumo, é o termo preponderante. Nesse mesmo sentido, segundo Ribemboim (1997), a centralidade do padrão de consumo no desequilíbrio ambiental se deve a seus impactos em todas as outras questões a ele associadas, como o uso da água, da energia, do solo, a configuração dos espaços urbanos, a questão das florestas, da poluição, da atmosfera, da fauna, da flora, etc.

Assim, uma das grandes questões que estão postas para a humanidade é como satisfazer a demanda mais elevada por bens e serviços, que resulta do aumento da renda, sem pôr em xeque a sustentabilidade ambiental do planeta. A resposta a esta questão deve considerar como pano de fundo pelo menos três constatações: i) o padrão de consumo nos países desenvolvidos é muito superior ao dos países do Sul; ii) as elites econômicas dos países do Sul dispõem de padrão de vida comparável ao das populações dos países desenvolvidos; e iii) o nível de renda de países do Sul com grandes contingentes populacionais, entre eles o Brasil, cresceu aceleradamente nos últimos anos. Desse pano de fundo, infere-se a magnitude do conflito político que permeia o desenvolvimento sustentável do planeta, que pode ser observado nas difíceis negociações sobre mudanças climáticas realizadas anualmente nas Conferências das Partes (COPs), no âmbito da Convenção-Quadro das Nações Unidas sobre Mudanças Climáticas, como a ocorrida em Doha em 2012. A seguinte passagem de Nascimento e Vianna (2007, p. 10) sintetiza, em parte, o mencionado conflito político:

Aqueles que detêm uma qualidade de vida altamente consumidora de energia e recursos naturais, como os norte-americanos e europeus, não estão dispostos a abdicar de seu estilo de vida, e os asiáticos, latino-americanos e africanos que ainda não acederam a esse padrão de vida se sentem no direito de fazê-lo - eis a questão, em resumo. 
No que se refere apenas ao conflito político entre os países do Sul e os ditos desenvolvidos, há de se levar em conta que o padrão de consumo vivenciado nesses últimos tem sido acusado de produzir a maior parte das emissões dos gases de efeito estufa do planeta, os quais são responsáveis pelo aquecimento da Terra. Tal padrão também é apontado como responsável pela maior pegada ecológica per capita gerada pelos países desenvolvidos, quando comparada à produzida pelos habitantes do Sul. A esse respeito, segundo o Living Planet Report 2012 (World Wildlife Fund, 2012), países com elevada renda per capita, como Qatar, Kwait, Dinamarca, Estados Unidos, Bélgica, Canadá, Austrália, entre outros, encabeçam a lista das maiores pegadas ecológicas per capita do mundo. Dessa maneira, tais países são os maiores responsáveis pelo "overshooting” ecológico do planeta de 1,5 ano em 2008. Em outras palavras, a Terra precisava, em 2008, de 1,5 ano para regenerar os recursos naturais renováveis consumidos e absorver o dióxido de carbono emitido em 1 ano.

Tendo isso em vista, vários autores, como Anderson (2012), Martínez Alier (2012) e Bursztyn (2007) consideram que os sacrifícios econômicos demandados atualmente para se atingir o desenvolvimento sustentável devem recair diferentemente entre os países. De acordo com Bursztyn (2007, p. 90):

$\mathrm{O}$ fato de existirem sociedades que ainda estão bem aquém dos níveis mínimos e satisfatórios de bem-estar material deixa essas sociedades numa situação em que não podem ser objeto das mesmas propostas auto-restritivas formuladas a partir das realidades dos países mais afluentes.

Já os argumentos de Anderson (2012) e Martínez Alier (2012), de que os países desenvolvidos devem arcar com os maiores sacrifícios econômicos com vistas ao equilíbrio ambiental, respaldam-se também em outro fundamento: esses países são os responsáveis históricos pela utilização da maior parte do "orçamento de carbono" 10 do planeta, de modo que seriam "devedores ambientais" dos países do Sul. Em outros termos, por terem sido os maiores responsáveis pelas emissões acumuladas de dióxido de carbono até o momento, os países desenvolvidos já utilizaram desproporcionalmente os créditos de emissão de carbono daquele orçamento, devendo deixar, doravante, relativamente maior parcela do citado orçamento para ser utilizada pelos países do Sul em seus esforços de desenvolvimento.

A despeito disso, a busca pelo desenvolvimento sustentável deve se tornar mais complexa na medida em que o crescimento da renda em populosos países do Sul tende a produzir, em breve, uma massa de novos "consumidores globais". Segundo Gardner, Assadourian e Sarin (2004, p. 5) apud Hogan e Mello (2007), tais consumidores percebem uma renda anual de, no mínimo, US\$ 7.000 (paridade de

(10) O termo orçamento de carbono (carbon budget) foi utilizado em Anderson (2012, p. 21), quando tal autor abordou a relação entre emissão acumulada de dióxido de carbono e mudança climática. 
poder de compra). Nesse sentido, de acordo com Hogan e Mello (2007), uma "explosão consumista" nos aguarda, e deverá ser oriunda do Sul, haja vista o enorme potencial de crescimento da classe de consumidores globais nos grandes países em desenvolvimento, dentre eles, China, Índia e Brasil. Segundo esses autores, em um futuro não muito distante, somente China e Índia poderão gerar mais 2 bilhões de novos potenciais consumidores globais. A trajetória de crescimento da renda nacional bruta per capita apresentada no Gráfico 8 indica a tendência de elevação do consumo que provavelmente virá pela frente.

\section{Gráfico 8}

Renda Nacional Bruta per capita (US\$) - Brasil, China e Índia (2005-2011)

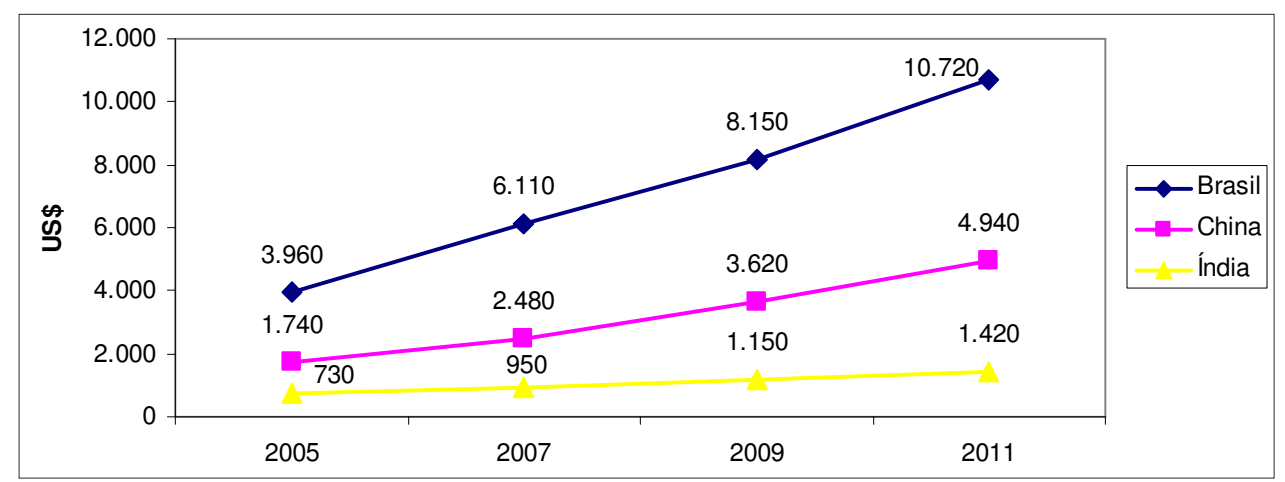

Fonte: Banco Mundial (Informação obtida de http://data.worldbank.org/, em maio de 2013). Elaboração própria.

No caso brasileiro, com o aumento do percentual da população nos estratos de renda superiores, o país segue no caminho de gerar novos consumidores globais. Segundo Brasil (2012e), o direito de as classes emergentes satisfazerem seus desejos de consumo, negados por tanto tempo, é compreendido e frequentemente incentivado. Nesse sentido, se dispuserem de dinheiro, essas populações irão satisfazer a sua demanda reprimida. Da mesma forma que as populações dos países desenvolvidos e as elites econômicas do Sul, essas pessoas também se julgam no direito de desfrutar das comodidades e facilidades proporcionadas pela vida moderna, por meio do consumo. Não há como, levando-se em conta o princípio da igualdade entre os homens, negar esse direito. Ademais, todos os cidadãos são massivamente instigados a consumir pelos meios de comunicação. Como lembra muito bem Santos (2011, p.131), "A cada dia, nessa época de globalização, apresenta-se um objeto novo, que nos é mostrado para provocar o apetite."

Para além desse conflito político de grandes proporções, a busca pelo desenvolvimento sustentável ainda colide com outro obstáculo ingente: a essência do modo de produção capitalista, a acumulação de capital. Como se sabe, a renda do capitalista é o lucro, ou os juros, no caso do investidor financeiro. E a massa de lucro, 
dada uma mesma taxa de lucro, será tanto maior quanto mais elevado for o volume de capital investido. Geralmente, parte do lucro é consumida pelo capitalista, como meio de vida, e outra parte é reinvestida no processo produtivo, perfazendo a reprodução ampliada do capital, a qual, se realizada continuamente, resulta no processo de acumulação. Desse modo, cada capitalista é estimulado a crescer, contribuindo assim para a expansão econômica como um todo.

A busca pelo lucro tende a se tornar mais obsessiva quando a empresa abre seu capital aos acionistas. Nesse caso, a empresa é pressionada a dar lucro no curto prazo, haja vista que, se essas ações não se mostrarem uma boa aplicação, os investidores irão preferir outros ativos, que concorrem com essas ações. E, novamente, a massa de lucro será maior de acordo com a elevação do volume do capital aplicado, o que estimula o crescimento econômico. Nesse sentido, segundo Brasil (2012e), o mundo corporativo é super "curto prazista", porque o "resultado do trimestre pode valorizar ou desvalorizar a sua ação".

Além da motivação pelo lucro, o capitalista, frequentemente, é impelido a crescer. Na verdade, a expansão econômica pode se tornar condição de sobrevivência de cada capitalista isolado. No processo de centralização do capital desencadeado pela concorrência - processo em que os capitais escapam das mãos dos capitalistas falidos para serem acumulados pelos concorrentes vitoriosos -, "os capitais grandes esmagam os pequenos" (Marx, 1968, p. 727). Grandes capitais têm a seu favor maiores economias de escala, concentram investimentos mais elevados em pesquisa e desenvolvimento, obtêm maiores descontos em suas compras, taxas de juros mais vantajosas em seus empréstimos, dentre outras vantagens. Assim, crescer é preciso.

Pelo exposto, infere-se que o crescimento é inerente ao modo de produção capitalista. Dessa maneira, visando ao desenvolvimento sustentável, por meio da redução do padrão de consumo, indaga Brasil (2012e, p. 44): "como convencer acionistas, empresários, vendedores e afins a incentivarem o cliente a consumir menos de seu produto?" Isto seria completamente contraditório com a prática vigente.

Baudrillard (1995), apud Meressi e Silva (2012), lembra-nos que a atual ordem de produção sobrevive ao preço do extermínio ou do perpétuo suicídio dos objetos (descartáveis, bens com curta vida útil, obsolescência acelerada dos produtos), baseados seja na própria "sabotagem" tecnológica aplicada nesses bens, seja na moda. Segundo Baudrillard (1995), isso constitui a solução desesperada, mas vital, de um sistema econômico e político em perigo de naufrágio; a Sociedade de Consumo precisa de seus objetos para existir e sente, sobretudo, a necessidade de destruí-los. E tal constatação vai frontalmente de encontro ao objetivo de redução do patamar de consumo com vistas ao desenvolvimento sustentável. 
Ademais, o crescimento econômico não é objetivo exclusivo de capitalistas. Governos e trabalhadores também perseguem o aumento do PIB, visto que, geralmente, o aquecimento da economia tende a reduzir o desemprego e a favorecer a elevação dos salários. Da mesma forma, maior crescimento também tende a aumentar a arrecadação pública, propiciando maior volume de recursos para os programas governamentais. Por fim, se a população se eleva, para que se mantenha a mesma renda per capita, faz-se necessário o crescimento. Nesse sentido, todos os interesses parecem convergir para o incremento do produto.

Diante das resistências para se reduzir o crescimento econômico e o consumo, alguns especialistas apostam na ecoeficiência para se alcançar o desenvolvimento sustentável, depositando suas esperanças especialmente nas novas tecnologias enquanto poupadoras de energia e matérias-primas (desmaterialização). Mas o que "aparenta" estranheza é o fato de os países mais avançados tecnologicamente serem justamente aqueles que, atualmente, mais danos têm provocado ao meio ambiente, haja vista suas maiores pegadas ecológicas per capita, e as elevadas - e também crescentes - emissões de gases de efeito estufa. Isso contribui para corroborar a tese defendida por Sawyer (2001), da preponderância do consumo (afluência) sobre os outros fatores da equação do impacto ambiental (população e tecnologia).

O caso das novas tecnologias, como instrumento da ecoeficiência, é emblemático, na medida em que, frequentemente, os homens depositam na ciência e na técnica a responsabilidade pela solução de seus problemas. Não raro, invoca-se o seguinte argumento: no futuro, o homem, por meio da ciência e da tecnologia, alcançará a solução para a problemática ambiental. Todavia, em se mantendo o modus operandi do sistema de produção capitalista, que persegue o crescimento econômico, os impactos das novas tecnologias podem ser ambíguos: se por um lado, tecnologias ambientalmente mais eficientes podem contribuir para o menor consumo de energia e de matérias-primas, por outro, ao contribuírem para preservar o dinamismo econômico, podem ter como resultado a anulação dos ganhos decorrentes da desmaterialização. A esse respeito, a passagem de Bursztyn e Bursztyn (2012, p. 284) é esclarecedora:

Os ganhos de eficiência induzidos pelo progresso tecnológico podem ser benéficos para o meio ambiente (ao economizar matérias primas e energia), mas podem também incentivar o consumo de recursos naturais (ao reduzir o ciclo de vida dos produtos e ao massificar o seu consumo). $\mathrm{O}$ aumento global do PIB (a riqueza produzida pela sociedade), ao se traduzir em maior poder aquisitivo, serve de contraponto, neutralizando as possíveis consequências benéficas da diminuição da intensidade de uso dos recursos naturais por unidade produzida. Nos países membros da OCDE se constata que os efeitos de escala resultantes do crescimento econômico (obtidos via intensificação do 
nível de produção) têm maior importância do que os avanços da eficiência (obtidos via tecnologia) (Vallée, 2002).

Assim, diante de todo o exposto neste artigo, considerando que os países desenvolvidos e as elites econômicas do Sul são os grandes responsáveis históricos pela degradação ambiental do planeta e que esse contingente já atingiu patamar de consumo que configura uma situação de desperdício social, entende-se que cabem a eles os sacrifícios socioeconômicos necessários para compensar os impactos ambientais decorrentes dos esforços de desenvolvimento das populações pobres do Sul, de modo compatível com a sustentabilidade do planeta. Entretanto, tendo em vista os impasses nas negociações internacionais sobre mudanças climáticas e o processo histórico da expansão da modernidade e do capitalismo pelo mundo, parece mais provável que em vez dos mencionados sacrifícios, os ricos intentem transferir os encargos para as populações mais pobres, o que constituiria apenas mais uma injustiça social no processo de desenvolvimento da sociedade mundial. A solução vislumbrada, o avanço tecnológico, até o presente momento parece impotente, haja vista as "crescentes" emissões de gases de efeito estufa verificadas nos últimos anos.

\section{Considerações finais}

Algumas políticas públicas implementadas pelo governo brasileiro no passado recente, como a expansão do crédito, a ampliação das transferências progressivas de renda associadas à política social e a política de valorização real do salário mínimo tiveram como um de seus resultados a elevação do percentual da população nos estratos superiores de renda (classes média e alta). Nesse sentido, o incremento na renda nacional parece contribuir para a melhoria da qualidade de vida dos segmentos mais pobres ao ampliar seu padrão de consumo, haja vista que vários bens e serviços ainda não estão disseminados por todas as classes.

Essa elevação no padrão de consumo deverá acarretar maior pressão sobre o meio ambiente, quer como provedor de recursos, quer como receptáculo de resíduos. Tal situação se agrava na medida em que outros populosos países em desenvolvimento também estão vivenciando este mesmo processo de aumento da renda, o que deverá gerar um gigantesco contingente de novos consumidores globais em um futuro próximo.

Tendo em vista que os recursos naturais são limitados, a grande pergunta é quem se apropriará deles, e em que proporção. As populações pobres do Sul julgamse no direito de fazê-lo, visto que, até o momento, os países desenvolvidos e as elites econômicas do Sul são apontados como os maiores responsáveis pela insustentabilidade ambiental, sendo os respectivos padrões de consumo o principal vetor da degradação do meio ambiente. Dessa forma, a questão do desenvolvimento sustentável enseja um grande conflito político, uma vez que, a julgar pelas recentes negociações internacionais, nenhum ator está aceitando sacrifícios econômicos em 
troca da sustentabilidade ambiental. Os ricos, sejam do Sul, sejam do Norte, não querem reduzir seus padrões de vida, o que implicaria também, nos termos atuais, menor dinamismo econômico, perda de renda e provavelmente de empregos. E os pobres do Sul consideram que, por terem conquistado os recursos necessários às aquisições, agora também têm o direito de consumir os bens proporcionados pela modernidade.

A questão adquire maior grau de complexidade na medida em que o modo de produção capitalista tende sempre a perseguir o crescimento, seja pelo desejo de ampliação das rendas dos capitalistas, ou por uma imposição da sobrevivência no mercado em face da concorrência, ou para manter ou elevar os níveis de emprego e salário, ou para proporcionar maior arrecadação pública, ou ainda para preservar a magnitude da renda per capita em um contexto de crescimento populacional.

Uma possibilidade vislumbrada para aliar crescimento econômico com sustentabilidade ambiental recai nas novas tecnologias a serviço da ecoeficiência. Contudo, como foi visto, novas tecnologias podem ter impactos ambíguos sobre o meio ambiente. Partindo da hipótese de que os avanços tecnológicos contribuem para a sustentabilidade ambiental, tais avanços teriam de ocorrer em um ritmo mais célere, visto que os indicadores ambientais mostram uma degradação crescente e sobremaneira preocupante, sobretudo no tocante ao aquecimento global. Todavia, há de se ter muita cautela com a implementação das novas tecnologias, cujos riscos para a humanidade são desconhecidos - tendo como exemplos os acidentes nucleares e as incertezas que cercam os transgênicos. Por fim, esses avanços tecnológicos "verdes" não deveriam implicar elevações nos preços dos bens, visto que, assim, a população mais pobre teria acesso dificultado a esses produtos, sendo, mais uma vez, alijada de boa parte das benesses da modernidade.

\section{Referências bibliográficas}

ANDERSON, K. Climate change going beyond dangerous - Brutal numbers and tenuous hope. Development Dialogue, Sept. 2012.

BAUDRILLARD, J. A sociedade de consumo. Lisboa: Edições 70, 1995.

BRASIL. Ministério da Fazenda. Economia Brasileira em Perspectiva. Brasília: $15^{\circ}$ Edição: abr. 2012a.

. Ministério da Fazenda. Economia Brasileira em Perspectiva. Brasília: $17^{\circ}$ Edição, dez. 2012b.

. Ministério da Previdência Social. Boletim Estatístico da Previdência Social, v. 17, n. 4, abr. 2012.

. Secretaria de Assuntos Estratégicos. Comissão para Definição da Classe Média no Brasil, 2012. 
BRASIL. Ministério do Meio Ambiente. O que o brasileiro pensa do meio ambiente e do consumo sustentável. Brasília, 2012e.

BRUNDTLAND, Gro Harlem. Nosso futuro comum. Rio de Janeiro: Fundação Getúlio Vargas. 1987.

BURSZTYN, Marcel. Contribuições no debate. In: NASCIMENTO, Elimar P.; VIANNA, João Nildo. Dilemas e desafios do desenvolvimento sustentável no Brasil. Rio de Janeiro: Garamond, 2007.

BURSZTYN, Marcel; BURSZTYN, Maria Augusta. Fundamentos de política e gestão ambiental: caminhos para a sustentabilidade. Rio de Janeiro: Garamond, 2012.

DALY, Herman. Una economía de estado estacionário. Nueva Sociedad, n. 244, mar./abr. 2013. Disponível em: www.nuso.org.

DEPARTAMENTO INTERSINDICAL DE ESTATÍSTICAS E ESTUDOS SOCIOECONÔMICOS (DIEESE). Política de valorização do Salário Mínimo. São Paulo, dez. 2011. (Nota Técnica, n. 106).

MARTINE, George; TORRES, Haroldo; MELLO, Leonardo. Cultura do consumo e desenvolvimento econômico na era das mudanças climáticas. In: MARTINE, George; BARBIERI, Alisson; CARMO, Roberto L. População e sustentabilidade na era das mudanças ambientais globais. Belo Horizonte: ABEP, 2012.

MARTÍNEZ ALIER, Joan. O ecologismo dos pobres: conflitos ambientais e linguagens de valoração. São Paulo: Contexto, 2012.

MARX, Karl. O capital: crítica da economia política. Livro I, Volume II. Rio de Janeiro: Civilização Brasileira, 1968.

MELLO, Leonardo; HOGAN, Daniel. População, consumo e meio ambiente. In: HOGAN, Daniel J. (Org.). Dinâmica populacional e mudança ambiental: cenários para o desenvolvimento brasileiro. Campinas: Núcleo de Estudos de População (NEPO), Universidade Estadual de Campinas, 2007.

População, consumo e mudança climática. In: HOGAN, Daniel Joseph; MARANDOLA JR., Eduardo. (Org.). População e mudança climática: dimensões humanas das mudanças ambientais globais. Campinas: NEPO-Unicamp, 2009, p.109-135. Disponível em: http://www.researchgate.net/profile/Leonardo Freire de Mello/publication/276917985 Populao_consumo_e mudana_climtica/li nks/555b580208ae91e75e764ea7.pdf.

MERESSI, Fernando; SILVA, Maria de Fátima. S. A estratégia de desenvolvimento do Governo Brasileiro no período 2004-2011: reflexões à luz de uma educação 
emancipatória. In: CONGRESSO INTERNACIONAL INTERDISCIPLINAR EM SOCIAIS E HUMANIDADES, 1, Niterói, Universidade Federal Fluminense, 2012.

MORAN, Emilio F. Meio ambiente e ciências sociais: interações homem-ambiente e sustentabilidade. São Paulo: Senac, 2011.

NASCIMENTO, Elimar P. do; VIANNA, João Nildo. Dilemas e desafios do desenvolvimento sustentável no Brasil. Rio de Janeiro: Garamond, 2007.

RIBEMBOIM, Jacques (Org.). Mudando os padrões de produção e consumo: textos para o século XXI. Brasília: Ministério do Meio Ambiente, dos Recursos Hídricos e da Amazônia Legal, 1997.

SANTOS, Milton. Por uma outra globalização: do pensamento único à consciência universal. 20. ed. Rio de Janeiro: Record, 2011.

SAWYER, Donald. Consumption patterns and environmental impacts in a global socioecosystemic perspective. In: HOGAN, Daniel; TOLMASQUIM, Maurício (Eds.). Human dimensions of global environmental change: Brazilian perspectives. Rio de Janeiro: Academia Brasileira de Ciências, 2001.

Population and sustainable consumption in Brazil. In: HOGAN, Daniel; BERQUÓ, Elza; COSTA, Heloisa (Ed.). Population and environment in Brazil: Rio+10. Campinas: CNPD, ABEP, NEPO, 2002.

WORLD WILDLIFE FUND. Living Planet Report 2012: biodiversity, biocapacity and better choices. Disponível em: http://wwf.panda.org. 